\title{
Pandering and pork-barrel politics ${ }^{\varkappa}$
}

\author{
Eric Maskin ${ }^{\mathrm{a}, \mathrm{b}}$, Jean Tirole $\mathrm{c,d}, *$ \\ ${ }^{a}$ Higher School of Economics, Moscow, Russia \\ ${ }^{\mathrm{b}}$ Harvard University, Littauer Center, 1805 Cambridge Street, Cambridge, MA 02138, United States of America \\ ${ }^{\mathrm{C}}$ Toulouse School of Economics (TSE) and Institute for Advanced Study in Toulouse (IAST), University of Toulouse Capitole, France \\ ${ }^{\mathrm{d}}$ Manufacture des Tabacs, 21 allee de Brienne, Toulouse cedex 6 Fr 31015, France
}

\section{A R T I C L E I N F O}

\section{Article history:}

Received 8 September 2014

Received in revised form 25 April 2019

Accepted 26 April 2019

Available online $\mathrm{xxxx}$

\section{JEL classification:}

$\mathrm{H} 1$

H7

K4

\section{Keywords:}

Accountability

Pandering

Deficit bias

Redistributive politics

Budget caps

\begin{abstract}
A B S T R A C T
We develop a model of pork-barrel politics in which a government official tries to improve her reelection chances by spending on targeted interest groups. The spending signals that she shares their concerns. We investigate the effect of such pandering on public spending. Pandering increases spending relative to a nonaccountable official (one who does not have to run for reelection) if either the official's overall spending propensity is known, or if it is unknown but the effect of spending on the deficit is opaque to voters. By contrast, an unknown spending propensity may induce the elected official to exhibit fiscal discipline if spending is transparent.
\end{abstract}

(c) 2019 Elsevier B.V. All rights reserved.

\section{Introduction}

In a representative democracy, a government is usually elected by a coalition of groups who expect it to press for their interests. This provides the government with the incentive to demonstrate its congruence with those interests. Indeed, observation suggests that public officials and their staffs spend substantial time, energy, and resources figuring out how to appear sympathetic to the concerns of interest groups, a behavior rarely accounted for by existing theories.

This paper develops a framework for studying pork-barrel spending that signals a government's concern for, or a shared identity with,

\footnotetext{
¿ We are grateful to two referees, Tim Besley, Aimé Bierdel, Mathias Dewatripont, Nathan Hendren, Brian Knight, Paul-Henri Moisson, and Steve Tadelis for their very helpful comments. The NSF (National Science Foundation) grant agreement no. SES-1238467 and the Rilin Fund (Eric Maskin) and the European Research Council (European Community's Seventh Framework Programme (FP7/2007-2013) grant agreement no. 249429 and European Union's Horizon 2020 research and innovation programme, grant agreement no. 669217) (Jean Tirole) provided research support.

* Corresponding author.

E-mail addresses: emaskin@fas.harvard.edu (E. Maskin), jean.tirole@tse-fr.eu (J. Tirole).
}

its constituents. We suppose that the electorate is uncertain about a public official's preferences over interest groups. A voter - at least one whose vote is motivated by his private interests - would like to re-elect the official if she has appeared to put sufficient weight on his concerns. Such retrospective voting ${ }^{1}$ provides the official with an incentive to direct benefits to him (i.e., to conduct pork-barrel spending). In essence, she would like to tell the voter: "I care about you."

We show that this incentive tends to generate too much public spending (or equivalently an excessive deficit if taxes are kept constant), but that there are three qualifications to this result. First, the very inefficiency of pork - the fact that the electorate overall typically loses more from it than the targeted interest groups gain - places some restraint on the official. Second, if the official's overall spending propensity is unknown and at least a portion of public spending must appear on the public balance sheet, a high spending level will be perceived as a bad signal by the electorate. Thus, the official will be

\footnotetext{
1 Retrospective voting plays a central role in Ferejohn's (1986) classic article. In our paper, retrospective voting is rationally derived from the voter's updating about the official's preferences.
} 
torn between her desire to please interest groups and her awareness that too much spending can backfire. We characterize the conditions under which public disclosure of fiscal deficits can actually lead to low public spending. Third, limits on fiscal deficits are sometimes legally imposed, as with the Stability and Growth Pact in Europe or balanced budget requirements in U.S. states. Even so, we show that they can have unfortunate side effects because of "crowding out" and "time shifting." Specifically, deficit caps induce the official to cut down not only on pork but also on useful public spending. Such caps further introduce a bias toward high-cost projects that frontload benefits and backload expenditure.

The paper is organized as follows. Section 2 lays out the basic model. Section 3 assumes that the public official's spending propensity is known; there is uncertainty about her preferences (namely, which interest groups she prefers), but not about the total spending she would like to do. This section shows how, in the absence of a budget cap, pork-barrel politics lead to overspending. The contribution of Sections 2 and 3 lies in the construction and analysis of a simple but unusual model of signaling through pork spending. We believe that our equilibrium existence, uniqueness and characterized results are of theoretical interest. The main contribution to political economy is the (simple but important) finding that accountable officials - by which me mean "officials subject to reelection" - distribute more pork than non-accountable ones, as well as to establish that key insights from the literature (such as the determinants of interest groups' ability to attract pork) carry over to our model.

The richer insights for political economy can be found in Sections 4 and 5. Section 4 considers the impact of a constitutional limit on budget deficits. A spending cap induces two types of distortions: it encourages the official to move expenditures off balance sheet, at a potential cost for public finances; and it crowds out useful public spending, not only pork. We provide an explanation for why elected officials are in practice granted larger discretionary budgets than non-elected ones. The idea is that elected officials, having higher career concerns, are more tempted to spend on pork and so imposing a tight budget would generate high levels of off-balance-sheet activities and low levels of useful public spending.

Section 5 introduces uncertainty about the official's desired spending level, and examines how the degree of budget transparency affects overall spending. Policy is opaque when an interest group observes only the pork it receives itself; it is transparent when the group also observes total spending. Opaque policymaking yields the same pandering outcome as under symmetric information about the official's spending propensity, except that for very costly pork there exists a second, "Groucho Marx" equilibrium in which the official spends only on her favorite interest groups and is reelected by non-beneficiaries, as not receiving pork is a good signal that the official's spending propensity is low. Transparency potentially allows the official to signal her thriftiness and can lead to greater restraint on spending. Section 6 offers a brief summary and a few ideas for further work. Proofs omitted in the text can be found in the Appendix.

\subsection{Relationship to the literature}

Although we believe our model offers a new perspective on pork-barrel politics, it is, of course, related to various strands of the existing literature. Our excessive-spending results are connected to the broader literature on deficit bias. ${ }^{2}$ Much of that literature assumes that interest groups impose an externality on other parties; that is, their spending is partially financed by these other entities. Sometimes these other parties are future voters or governments

\footnotetext{
2 A review of this literature and an assessment of its relevance can be found in Calmfors (2005).
}

(Persson and Svensson, 1989; Alesina and Tabellini, 1990; Aghion and Bolton, 1990); ${ }^{3}$ sometimes they are other subgovernments under fiscal federalism (as in Argentina or Brazil); and sometimes they are current interest groups (Velasco, 2000; Battaglini and Coate, 2007, 2008). In the Battaglini-Coate models, the legislature chooses spending on public goods as well as on district-targeted pork. The models show that forcing the legislature to balance its budget (or, more generally, constraining its ability to smooth shocks by issuing debt) increases welfare when the country's tax base is large (relative to public spending needs), but not when it is small ${ }^{4}$.

In the literature on "Ramsey electoral promises," campaigning politicians make binding promises to various interest groups subject to an overall budget constraint (Dixit and Londregan, 1996, 1998; Lindbeck and Weibull, 1987; Myerson, 1993) or, more generally, subject to the requirement that debt be issued to finance a budget deficit (Lizzeri, 1999). These theories, too, involve an externality, except that it is mediated by a government courting interest groups, rather than by interest groups themselves. In Lizzeri and Persico (2005), "bad" (pork-barrel) public spending is assumed to be more targetable than "good" (public good) public spending. That paper shows that the set of parameters for which pork-barrel spending occurs in equilibrium grows with the number of candidates.

The central contribution of our approach is to add asymmetric information to these literatures: The official signals to the electorate at large as well as to individual interest groups. Specifically, in contrast with earlier work, we emphasize the pandering component of pork-barrel spending, as well as the effects of deficit transparency and opaqueness. In the Ramsey literature, the beneficiaries of pork are those whose vote is pivotal to getting an official elected. Our work is instead aimed at the complementary phenomenon of pandering by politicians who are already in office and are targeting groups that may have contributed little to their electoral campaign.

The literature on common agency (Grossman and Helpman, 1994; Dixit, 1996) emphasizes the role of bribes/campaign contributions in determining policy. ${ }^{5}$ In this line of work, groups commit to making policy-contingent payments to a politician. The success of an interest group in attracting pork then corresponds not to its role in elections, but to its ability to bribe politicians. This literature is therefore quite different from our paper.

In an important and closely related contribution, Gavazza and Lizzeri (2009) study an election model in which two candidates credibly promise transfers to $n$ distinct ex-ante identical interest groups, which then vote stochastically as a function of the utility differential promised by the candidates. These transfers are financed through distortionary taxation on labor. Deficits can be financed by borrowing abroad. Under transparency, no transfers are promised. But if groups observe their own transfer perfectly and the transfers to other groups only in a noisy way, budget deficits emerge. Furthermore, the

\footnotetext{
3 Martimort (2001) revisits the Persson-Svensson-Alesina-Tabellini model (Persson and Svensson, 1989; Alesina and Tabellini, 1990) of the commitment value of budget deficits from the standpoint of redistribution (Mirrlees, 1971). He supposes that governments are inequality averse (left-wing governments more so than right-wing ones). He shows how a left-wing government is both hurt by a budget deficit (the future marginal utility of income increases) and helped by it (a right-wing government tomorrow will be constrained to adopt a more redistributive policy). One historical cause of deficit bias, dynamically inconsistent monetary policy, has become less important in recent years with the growth of independent central banks, which by and large have refrained from using inflation surprises to finance fiscal deficits.

4 Drazen and Ilzetzki (2013) emphasize a different cost of attempts to constrain the distribution of pork. In their model, the agenda setter has private information about the value of a public good; pork acts as a signalling device and greases the legislative wheels.

5 In Bennedsen and Feldmann (2002, 2006), interest groups can influence policy both by offering contributions and by providing information favorable to the group. The focus is on determinants of the form of influence, and on whether competition generates more decision-making-relevant information.
} 
impact of transparency of transfers differs from that of transparency of revenue.

Gavazza and Lizzeri's focus on electoral promises and ours on policy while in office are complementary; electoral promises probably are most relevant for year 1 in office and on a stand-alone basis would predict decreasing expenditures over the political tenure while our model predicts higher expenditures prior to an election. ${ }^{6}$ Besides this complementarity, the main distinctions between the two papers are twofold: First, our model is one of signaling (to each group and to the electorate as a whole). Second, we study the impact of tenure/accountability, while the Gavazza-Lizzeri model takes the politician's stake and therefore career concerns as exogenous.

The strand of literature most closely related to our paper assumes that an official acts so as to signal her congruence with the electorate (Maskin and Tirole, 2004) or her ability to implement public projects (Alesina and Tabellini, 2007, 2008; Canes-Wrone et al., 2001; Dewatripont et al., 1999; Dewatripont and Seabright, 2006; Rogoff, 1990; Rogoff and Sibert, 1988). The key difference between our work and this previous literature is that now public spending is strategically targeted to heterogeneous constituencies (a feature borrowed from the Ramsey literature) ${ }^{7}$

Drazen and Eslava (Drazen and Eslava, 2006, 2010, 2013) develop models of spending as a mechanism to signal politicians' unobserved preferences. Those papers and this one concentrate on sufficiently different applications as to make them complementary. They share the idea that rational voters support an incumbent who targets them before the election even though they know this targeting is electorally motivated. Drazen and Eslava (2013), for example, consider non-monotonicities in electoral effects of targeting as well as implications for cycles in the composition of spending, as in Drazen and Eslava (2013). However, there are some important modeling differences. The Drazen and Eslava papers, unlike ours, consider a known, fixed budget with no deficit. Consequently, being targeted cannot lead to negative inferences, and overall fiscal conservatism cannot arise, unlike in Section 5 of our paper. Furthermore, our model includes the possibility of off-balance-sheet spending. Finally, our paper provides a comparison between accountable and nonaccountable officials, both in their spending behavior and in the fiscal constraints they are likely to face.

Lastly, we should mention that there is a large literature in which the officials try to signal their ability rather than their preferences among interest groups (Rogoff, 1990; Prat, 2002; Coate, 2004). However, that literature does not touch on pork barrel spending, the topic of this paper.

\section{The model}

There are two dates $t=1,2$. A "public official" or "incumbent" chooses a policy at date 1 , and then voters decide simultaneously whether or not to vote for her re-election. If a majority vote in her favor, ${ }^{8}$ the official chooses another policy at date 2 . If not re-elected, she is replaced by another official, who chooses the date- 2 policy.

The electorate consists of a set of "minorities" or "interest groups". For simplicity, we will assume a continuum of interest groups uniformly distributed on $[0,1]$. The official's date- 1 policy is a choice, for each interest group $j \in[0,1]$, of a spending level $\hat{y}_{j} \in\{0,1\}$. That is, we assume, for now, that pork is indivisible (we consider divisible pork in Section 3). Spending level $\hat{y}_{j}=1$ yields benefit $B$ to

\footnotetext{
6 Brender and Drazen (2013) find that new democracies increase their expenditures during election years, while established democracies are more prone to punish profligates (but nonetheless witness large expenditure composition change during election year).

7 See Panova (2009) for a model in which politicians signal their preferences among constituents twice: during the campaign, and while in office.

8 We assume that if exactly half the electorate votes for her, she is reelected.
}

interest group $j$ and costs $L>B$ to the electorate as a whole. Spending level $\hat{y}_{j}=0$ yields no benefit and costs nothing. Thus, in this simplest version of the model, public spending is pure pork - i.e., socially wasteful. (We will later generalize the analysis to accommodate useful spending as well.) The net welfare of interest group $j$ at date 1 is therefore

$\hat{y}_{j} B-y L$, where $y=\int_{0}^{1} \hat{y}_{k} d k$.

The date- 2 policy (chosen either by the incumbent or her replacement) is completely analogous to the one at date 1 .

Throughout this paper we consider two alternative assumptions about which aspects of a policy interest groups can observe. In the opaque case, we suppose that interest group $j$ observes only the pork $\hat{y}_{j}$ it receives itself. In the transparent case, $j$ observes $\hat{y}_{j}$ and also total spending $y$.

Key to our modeling is the idea that the official is more interested in some interest groups than in others, either because of her intrinsic preferences or because she has different stakes in the welfare of different groups. We formalize this by considering a set of weights $\left\{\alpha^{i}\right\}_{i \in[0,1]}$, where $\alpha^{i}$ is a real number (possibly negative) that is increasing in $i$ and $\int_{0}^{1} \alpha^{i} d i=1$. We assume that, for all $j$, the official puts weight $\alpha^{\omega(j)}$ on group j's welfare, where $\omega$ is a one-to-one mapping from $[0,1]$ to itself. We call $\omega$ the official's type.

We wish to capture the idea that although interest groups all know the set of weights $\left\{\alpha^{i}\right\}_{i \in[0,1]}$, no group knows the particular weight that the official assigns to it. Formally, we suppose that $\left\{\alpha^{i}\right\}_{i \in[0,1]}$ is common knowledge but that an interest group regards all types $\omega$ as equally likely. If a new official comes in at date 2, we assume that her type is drawn independently from the same uniform distribution.

From an interest group's perspective, an official's policy is typedependent. We denote a policy by $\hat{\mathbf{y}} \equiv\left\{\hat{y}_{j}(\cdot)\right\},{ }^{9}$ where $\hat{y}_{j}(\omega)$ is the pork assigned to group $j$ when the official's types is $\omega$.

The official's welfare from policy $\hat{\mathbf{y}}$ when her type is $\omega$ is

$\mathbf{U}(\hat{\mathbf{y}}, \omega)=\int_{0}^{1} \alpha^{\omega(j)}\left[\hat{y}_{j}(\omega) B-y(\omega) L\right] d j=\left[\int_{0}^{1} \alpha^{\omega(j)} \hat{y}_{j}(\omega) d j\right] B-y(\omega) L$.

An especially simple class of policies comprises those of the "natural-pecking-order" variety, i.e., policies $\hat{\mathbf{y}}$ taking the form

$\hat{y}_{j}(\omega)= \begin{cases}1, & \text { for } \omega(j) \geq i^{0} \\ 0, & \text { for } \omega(j)<i^{0}\end{cases}$

for some cut-off $i^{0}$. In Section 3, we will show that a natural-peckingorder equilibrium (a perfect Bayesian equilibrium with a naturalpecking-order policy) always exists and that, under some conditions, it is the unique PBE. ${ }^{10}$

We can identify a natural-pecking-order policy $\hat{\mathbf{y}}$ with the corresponding total spending level $y=\int_{0}^{1} \hat{y}_{j} d j=\int_{i^{0}}^{1} d i$ (which is independent of the type $\omega$ ). Let $\alpha(y) \equiv \alpha^{i^{0}}$ and let $F(\alpha)$ be the proportion of interest groups for which $\alpha^{i} \leq \alpha$ (i.e., $F(\alpha)=\int_{\alpha^{\omega(j)} \leq \alpha} d j$ ). Then, we can write the official's welfare as a function of $y$ :

$U(y)=\left[\int_{\alpha(y)}^{\infty} \alpha d F(\alpha)\right] B-y L \equiv w(y) B-y L$,

\footnotetext{
9 Bold letters will refer to policy vectors.

10 A perfect Bayesian equilibrium is a type-contingent policy for the official and a vote for/vote against strategy and beliefs about the official's type for each interest group contingent on what the group can observe of the official's action (opaque or transparent) such that strategies are expected-payoff maximizing and weakly undominated and beliefs are correct in equilibrium.
} 
where $w(y) \equiv y M^{+}\left(F^{-1}(1-y)\right)$ is an increasing function of $y$, $y=1-F(\alpha(y))$ and $M^{+}(\cdot)$ is the truncated mean: $M^{+}(\hat{\alpha}) \equiv$ $\int_{\hat{\alpha}}^{\infty} \alpha d F(\alpha) /(1-F(\hat{\alpha}))$. Note that the official's utility is concave in spending: Using $1-F(\alpha(y))=y$,

$\frac{\partial^{2}}{\partial y^{2}}(U(y))=\frac{\partial}{\partial y}(\alpha(y) B-L)<0$.

Let $\alpha^{*}>1$ be defined by

$\alpha^{*} B=L$

If we let $x \equiv 1-F\left(\alpha^{*}\right)$, then $\alpha^{*}=\alpha^{1-x}$.

A non-accountable official of type $\omega$ - an official without reelection concerns - will find it optimal to choose a natural-pecking-order policy in which all interest groups $j$ with $\alpha_{\omega(j)} \geq \alpha^{1-x}$ get pork. She will spend $x$ on her $x$-favored groups. The same is true for an accountable official (or her replacement) at date 2 .

Sections 3 and 4 will assume that the spending propensity $x$ is known to the electorate, and Section 5 will relax this assumption.

In a natural-pecking-order equilibrium, the incumbent official's overall objective function ${ }^{11}$ is

$V \equiv U(y)+p(y) R$

where $p(y)$ is the (endogenous) probability that she is re-elected when spending $y$ on her $y$-favored groups and $R$ is her rent from holding office. This rent reflects the perks and ego gratification from holding office; it also embodies the official's payoff from distributing pork to her own favored groups at date $2 .{ }^{12}$ If $x \geq 1 / 2$, then, through her spending, even a non-accountable official would assemble a majority of the electorate in her favor in a thought experiment in which she would, after all, be subject to election. ${ }^{13}$ We shall assume, therefore, that

$x<1 / 2$.

As Section 3 shows, the official is not reelected if she targets solely her $x$-favored groups constituencies $(p(x)=0)$, but is reelected if she distributes pork to half of the electorate and thereby assembles a majority in her favor $(p(1 / 2)=1)$. Note that, since $x<1 / 2$, she will not want to provide pork to more than a majority. Henceforth we will assume that the politician is willing to do this - i.e., to pander to a majority - if this ensures her reelection; specifically, we posit that the rent from holding office satisfies

$R>U(x)-U(1 / 2)$

\footnotetext{
11 For more general policies $\hat{\mathbf{y}}$, this objective function is $V=\mathbf{U}(\hat{\mathbf{y}}, \omega)+p\left(\left\{\hat{y}_{j}(\omega)\right\}\right) R$, if the official is of type $\omega$.

12 Given that only a fraction $x$ of the incumbent's preferred groups will be favored by the new official (whose type is drawn independently), the incumbent would clearly prefer to distribute the pork herself. Of course, the assumption that the new official spends only on the proportion $x$ is artificial because it presumes that she does not need to worry about reelection. But a more elaborate model that incorporated accountability for the new official would generate the same quantitative conclusions.

13 Put differently, under natural-pecking-order strategies, the official's spending would not depend on her accountability or lack thereof.
}

\section{Basics of excessive spending}

\subsection{Pure pocketbook politics}

In this section and the next we assume that the electorate knows the official's spending propensity $x$. In this subsection, we further suppose that each interest group acts to maximize its expected pork (net of taxes) at date 2, i.e., it votes its "pocketbook" (in Subsection 3.2, we allow for ideological concerns too).

\subsubsection{Natural-pecking-order equilibria: the opaque case}

Let us assume for now that interest group $j$ observes only the pork it gets $\hat{y}_{j}$ and not the official's total spending $y$ (the opaque case). If the official's equilibrium policy takes a natural-pecking-order form and $y \notin\{0,1\}$ (we will soon establish the latter), then an interest group cannot detect a deviation from equilibrium, and so its probabilistic belief that it will be favored by the official at date 2 (should the official be reelected) when it receives pork at date 1 is

$\hat{x}=\left\{\begin{array}{ll}1, & x \geq y \\ x / y, & x<y\end{array}\right.$.

This means that $\hat{x}>x$, and so the interest group is strictly better off if the official is reelected than if she is replaced (since the replacement official will favor the interest group only with probability $x$ ). Thus, in this case, the weakly undominated strategy for the interest group is to vote for the official's reelection. ${ }^{14}$ By contrast, if it does not receive pork, its belief that it will be favored at date 2 (should the official be reelected) is

$\hat{x}=\left\{\begin{array}{ll}\frac{x-y}{1-y}, & x \geq y \\ 0, & x \leq y\end{array}\right.$,

implying that $\hat{x}<x$. Thus, when the interest group does not get pork, voting against the official's reelection is the weakly undominated strategy.

We conclude that the official will be reelected if and only if $y \geq$ $1 / 2 .{ }^{15}$ If the official chooses $y<1 / 2$, then it is clearly best for her to select $y=x$, yielding payoff

$U(x)$

If she chooses $y \geq 1 / 2$, then her payoff is

$U(1 / 2)+R$

\footnotetext{
14 Strictly speaking, the interest group cannot affect the official's reelection because it is just one group among a continuum. So, formally, we are analyzing the case of a large but finite number of interest groups.

15 A referee correctly pointed out that the pecking-order result has to be modified when there are large interest groups. However, the reason is not there may be groups "whose size make [them] important for [official's] reelection," but rather that there may be groups that are so large that they have to be jettisoned for the sake of other, smaller groups that are not as highly favored. For example, suppose there are three groups: group $A$ has size $1 / 4$ and gives the official a net payoff of 4 per group member; group $B$ has size $1 / 2$ and gives the official a net payoff of -1 per group member; and group $C$ has size $1 / 4$ and gives the official a net payoff of $-3 / 2$ per group member. $A$ pecking-order outcome would have the official give pork to groups $A$ and $B$. However, because group $B$ is "too big" (i.e., an integer problem arises), the official is better off with groups $A$ and $C$.
} 
In view of assumption (3), the unique natural-pecking-order equilibrium consists of the official choosing the natural-peckingorder policy with $y=1 / 2$ (which leads to her reelection). ${ }^{16}$

It turns out that there are no PBEs that are not natural-peckingorder equilibria. In Appendix A.1, we establish:

Proposition 1A (Opaque case). In the opaque case, there is a unique $P B E$, which is the unique natural-pecking-order equilibrium (and for which $y=1 / 2$ ).

Divisible pork. Let us suppose next the pork is divisible. More precisely, let us suppose that, for some small $\epsilon>0$, the official can allocate pork to an interest group in minimum increments of $\epsilon$ (up to a maximum allocation of 1 ). In this case, Proposition $1 \mathrm{~A}$ continues to hold. This is because the official will always give each of the $x$-favored groups $j$ the maximum amount of pork (i.e., $\hat{y}_{j}=1$ ), and if she gave any other group anything other than 1, it would know for sure that it is not $x$-favored.

\subsubsection{Natural-pecking-order equilibria: the transparent case}

We next return to indivisible pork and consider the transparent case, in which each interest group $j$ observes not just its own pork $\hat{y}_{j}$ but the official's total spending $y$. The unique PBE from the opaque case (which entails the natural-pecking-order policy for which $y=1 / 2$ ) is still an equilibrium in the transparent case $-y^{\prime} s$ observability only makes deviations more visible by interest groups.

But there are other equilibria as well. Indeed, any naturalpecking-order policy with total spending $y=y^{*}>1 / 2$, where $U\left(y^{*}\right)+R>U(x)$ can be sustained in perfect Bayesian equilibrium: if the official chooses $y=y^{*}$, then interest groups (correctly) have natural-pecking-order beliefs, and so vote for her if they get pork; if the official chooses $y \neq y^{*}$, an off-the-equilibrium path event, then each interest group believes it will not be favored by the official at date 2 , and so they all vote against her. For that matter, $y=x$ can also arise in an equilibrium sustained by these same out-of-equilibrium beliefs.

These also exist PBEs that are not natural-pecking-order equilibrium. For example, there is a PBE in which the official's equilibrium policy is $\hat{\mathbf{y}}$ for which, for all $\omega$,

$\hat{y}_{j}(\omega)=\left\{\begin{array}{l}1, \text { if } j<\frac{1}{2} \\ 0, \text { if } j \geq \frac{1}{2}\end{array}\right.$

provided that

$\mathbf{U}(\hat{\mathbf{y}}, \omega)+R \geq U(x)$ for all $\omega .{ }^{17}$

\footnotetext{
16 The pecking-order equilibrium result does not depend on interest groups being infinitesimal and pork being indivisible. Suppose to the contrary that there are only finitely many groups and that pork is divisible. Note first that if there are no upper bounds on total pork and how much pork any group can receive, the official will give an unbounded amount of pork to the most favored group. Assume therefore that the total amount of pork is bounded at $\bar{y}$. If there are no "integer problems" (see below for the case where there are such problems), then equilibrium will be a pecking-order equilibrium in which each group gets $2 \bar{y}$ (so total pork is $1 / 2 \times 2 \bar{y}=\bar{y}$ ). If the official tries to give some favored group more than $2 \bar{y}$, this will mean giving some other group less than $2 \bar{y}$, and with pessimistic expectations they will decline to vote for the official's re-election.

17 In equilibrium, those receiving pork vote against the official and those not receiving pork vote in favor. Any interest group that does not get what it is expecting believes that it is not $x$-favored by the official.
}

However, if we require the PBE to satisfy the D1 refinement ${ }^{18}$ (Banks and Sobel, 1987), then we get the following proposition (which is proved in Appendix A.2).

Proposition 1B (Transparent case). In the transparent case, the unique PBE satisfying the D1 refinement is the natural-pecking-order equilibrium with $y=1 / 2$.

Divisible pork. Interestingly, there are parameter values for which the official can get more than $U(1 / 2)+R$ in equilibrium when pork is divisible (unlike in the opaque case). Specifically, consider the policy $\mathbf{y}^{*}$ for which

$\hat{y}_{j}^{*}(\omega)=\left\{\begin{array}{l}1, \text { if } \omega(j)>1-\frac{x}{2(1-x)} \\ \epsilon, \text { if } \omega(j) \in\left[\frac{1}{2}, 1-\frac{x}{2(1-x)}\right] \\ 0, \text { otherwise. }\end{array}\right.$

For this policy, the less favored among the 1/2-favored interest groups receive only a small amount $(\epsilon)$ of pork.

This can be beneficial to the official because it allows her to give only $\epsilon$ pork to even less favored interest groups and still induce them to vote for her. Indeed, this policy is part of a PBE provided that

$\mathbf{U}\left(\mathbf{y}^{*}, \omega\right)>U\left(\frac{1}{2}\right)$ for all $\omega$.

See Appendix A.2 for more detail.

Proposition 1C (Divisible pork). When pork is divisible and in the transparent case, and focusing on equilibria that satisfy D1,

(i) The indivisible-pork equilibrium is still the unique equilibrium if

$$
K \equiv \int_{1 / 2}^{1-[x / 2(1-x)]}\left(\alpha^{i}-\alpha^{1-x}\right) d i \geq 0
$$

(ii) If $K<0$ (as is the case for affine $\alpha^{i}$ ), this equilibrium is no longer unique; it yields the official's lowest utility among equilibria satisfying D1. All equilibria involve a reelection by a majority of one half of the voters, but some may receive little pork.

The extra equilibria in the case $K<0$ arise because, when pork is divisible, the official may benefit from the following strategy: (i) giving her most favored groups maximal pork (as usual), and (ii) bunching the next-most-favored groups (to whom she would also distribute pork absent electoral concerns) with somewhat-leastfavored groups (to whom she would not) so as to build an overall reelection coalition of $1 / 2$, and giving them all minimal pork (epsilon). If the somewhat-least-favored groups attach sufficient probability to being next-most-favored when they get pork $\left(\frac{X-(1-x)}{X-(1 / 2)}=x \Longleftrightarrow X=\right.$ $1-\frac{x}{2(1-x)}$, where $X$ is the cutoff between most-favored and nextmost-favored groups), they will vote for re-election. The official gains by spending only minimally on them; her cost is that she must also spend only minimally on the next-most-favored groups. The gain of given less pork in $[1 / 2, x)$ outweighs the cost of giving less pork in $[x, X]$ when $K<0$.

\footnotetext{
18 A PBE satisfies the D1 refinement if for any out-of-equilibrium policy, interest groups assign zero probability to the official being type $\omega$ if there exists another type $\omega^{\prime}$ for which the set of interest groups' best responses causing the $\omega^{\prime}$-official to benefit from the deviation is strictly bigger than that for the $\omega$-official.
} 


\subsubsection{The role of accountability}

As in Maskin and Tirole (2004), we can compare the allocation resulting from an elected official to that which would prevail under a non-accountable official. If an official does not have to run for election, she will set $y=x$. We conclude, therefore, that an accountable official (representative democracy) leads to excessive spending.

We can also consider direct democracy, in which the fiscal policy is chosen by citizens and is not delegated to an official. There always exist a continuum of equilibria in which a collection of (slightly more than) half of the population forms and allocates the benefits to itself in a package referendum (this coalition is stable in the absence of monetary transfers). Direct democracy then yields $y^{D D}=1 / 2$. Appendix A.3 shows that when $B<L / 2$, all equilibria satisfying coalition-proofness á la Bernheim et al. (1987) yield this amount of pork.

\subsection{Extension: ideological voting}

We now extend Lindbeck and Weibull (1987)'s key insight on how targeted campaign promises are reflected in policy. We suppose that in group $j$ a fraction $v_{j}$, now possibly smaller than 1 , votes its pocketbook, i.e., maximizes its expected second-period benefit net of taxes. ${ }^{19}$ The remaining fraction $1-v_{j}$ votes "ideologically" (or, more generally, for reasons unrelated to the date- 1 policy, e.g., the candidate's character or appearance). Of these, a random fraction $\phi$ with cumulative distribution function $H$ and density $h$ on $[0,1]$ will vote for the incumbent and a fraction $1-\phi$ will vote for her rival, regardless of the date- 1 policy (we assume that $\phi$ is the same for all interest groups for notational simplicity). We assume that the density is nondecreasing $\left(h^{\prime} \geq 0\right)$. This assumption guarantees the concavity of the relevant programs.

In this setting, the official will not necessarily prefer to spend on interest groups $j$ for which $\alpha^{\omega(j)}$ is higher. Thus, the natural-peckingorder assumption on beliefs no longer makes sense as stated. But we can generalize it in the following way. A "generalized naturalpecking-order" equilibrium is such that beneficiaries of pork $\left(\hat{y}_{j}=1\right)$ vote for the incumbent, while the others vote against her. The two notions coincide under symmetric interest group greed (i.e. $v_{j}=v$ for all $j$ ).

Proposition 2 (Some ideological voting). If some of the electorate votes ideologically rather than pocketbook, there exists a unique generalized natural-pecking-order equilibrium, in which beneficiaries of pork, and only them, vote for the incumbent. Interest group ranked $j$ receives pork iff $\alpha^{\omega(j)} B+\frac{h}{1-v} v_{j} R \geq L$. Public spending increases with the level of rents from office and the intensity of electoral competition. An interest group is more likely to receive pork, the more pocketbook-oriented it is.

Proposition 2, which is proved in Appendix A.4, confirms for our model results that were developed in other setups. For instance, the idea that pocketbook-oriented groups are more likely to receive pork is reminiscent of "high clout" electoral groups being those who are more greedy, i.e. most likely to shift their votes in response to expected private consumption (Cox and McCubbins, 1986; Lindbeck and Weibull, 1987; Dixit and Londregan, 1996, 1998).

\section{Legal limits on spending to impose on an elected official}

The model in Section 3 incorporates the basic mechanics of porkbarrel spending. It presumes, however, that all public spending is wasteful, and so implies that a simple legal provision would be optimal: a prohibition on all public expenditure. We now turn to a richer

\footnotetext{
$\overline{19}$ One could also take $B$ and $L$ to be interest-group specific.
}

model in which some spending is worthwhile and nontrivial spending caps are called for. Constraints on government fiscal policy are common place in practice. For example, most U.S. states have a balanced budget requirement; the Stability Pact in the European Union limits the budget deficit to (cyclically adjusted) three percent of GDP and gross government debt to sixty percent of GDP, ${ }^{20}$ although the constraint has had only limited effectiveness; ${ }^{21}$ and in the United Kingdom, the deficit is not to exceed net capital formation (over the business cycle).

We will look at the optimal spending cap. Conceptually, our insights more broadly apply to "balanced budget requirements" and "deficit caps" too, but we cannot formally analyze those alternative constraints because our model does not explicitly deal with where the revenue for spending comes from (e.g., from taxes or debt).

Accordingly, we will assume that $y$ is at least partially verifiable by a court at date 1 (see below) and that a legal (constitutional or statutory) spending cap can be enforced. ${ }^{22}$

We will argue that using a spending cap to constrain pork-barrel spending runs into two difficulties. First, a tight budget constraint induces a substitution away from desirable public spending. And, second, it induces the politician to use spending technologies that are inefficient but whose costs are not immediately observable; i.e., it encourages the use of off-balance-sheet liabilities. Formally, suppose that the official faces a spending limit $G$. Assume that she chooses a pork-barrel policy $\hat{\mathbf{y}}$ with total expenditure $y=\int \hat{y}_{j} d j$ and also decides what fraction $\sigma$ of its cost is observable (how much is "on the balance sheet" ). Specifically, she chooses a level of transparency $\sigma(\leq 1)$ so that only $\sigma y L$ counts toward the spending limit but the actual cost is

$y L\left[\sigma+D_{1}(1-\sigma)\right]$,

where $D_{1}$ - the deadweight loss from distorting spending to keep it unobservable - satisfies $D_{1}(0)=0, D_{1}^{\prime}(0)=1$, and $D_{1}^{\prime \prime}>0$. The distinction between actual and observed spending and the concomitant deadweight loss reflect the many opportunities that governments have themselves to shift liabilities off-balance-sheet (e.g. changes in pension benefits or the provision of costly contingent guarantees on social accounts, individual assets, firms or central banks), or conversely to bring cash forward in time at the expense of future revenue (perhaps implying a discount on the sale of state assets). We assume that interest groups observe at least their own pork; that is, they are able to figure out what their benefit is, whether it is on- or off-balance sheet (presumably, if they do not, the official will explain to them when $\hat{y}_{j}=1$, as it is in her interest to do so).

Assume that, in addition to pork-barrel spending, the public official can undertake public good spending g generating surplus

$B_{0}-D_{2}\left(g_{0}-g\right)$

where $g_{0}$ is the first-best optimal public good level and $D_{2}(0)=0$, $D_{2}^{\prime}(0)=1$ and $D_{2}^{\prime \prime}>0$. For simplicity we will assume that all of $\mathrm{g}$ is on the balance sheet, although as in the case of pork spending, we could alternatively introduce a distinction between actual and observed spending without changing our conclusions (there are

\footnotetext{
20 Or if it exceeds these levels, to converge to it at "a satisfactory pace".

21 First, nations accumulate large off-balance-sheet liabilities, so that public debt vastly underestimates the actual government liabilities. Second, the enforcement mechanism has little bite; although it has been strengthened in the wake of the euro crisis, the governance of budget discipline remains a weak point of the eurozone construction.

22 A substantial literature in public finance discusses the credibility of such enforcement and the nature of the institutions that are likely to make it effective (see, in particular, Calmfors, 2005).
} 
many ways, including public-private partnerships, to frontload or backload public good expenditures). We assume that all citizens enjoy the public good equally, and so the provision of the public good does not convey any signal as to the politician's preferences among interest groups. ${ }^{23}$ Thus it does not matter whether voters observe $g$ or not. The model is otherwise the same as that of Section 3.2, with $v_{j}=v$ for all $j$ (so we can indeed focus on a natural-pecking-order equilibrium).

The politician is re-elected if and only if

$v y+(1-v) \phi \geq v(1-y)+(1-v)(1-\phi)$.

And so, if the official faces spending cap $G$, the optimal naturalpecking-order policy is given by:

$$
\begin{aligned}
& \max _{\{y, \sigma, g\}}\left\{\left[\int_{0}^{1} \alpha^{i} y_{i} d i\right] B-\left[y L\left[\sigma+D_{1}(1-\sigma)\right]+g\right]+B_{0}-D_{2}\left(g_{0}-g\right)\right. \\
& \left.\quad+\left[1-H\left(\frac{1-2 v y}{2(1-v)}\right)\right] R\right\}
\end{aligned}
$$

such that $\int_{0}^{1} y_{i} d i=y$ and

$g+\sigma y L \leq G$

Proposition 3 (Impact of a spending cap). In a natural-pecking-order equilibrium, a looser deficit cap increases pork-barrel spending. However, it also encourages desirable public-good spending and induces the government to use more efficient forms of pork with lower off-balancesheet liabilities. ${ }^{24}$

Next we explore the implications of variation in the rent $R$. For tractability reasons, we here assume that the density $h$ is uniform.

\section{Proposition 4 (Impact of rent from office).}

(i) Suppose that $H$ is distributed uniformly. Then, in a naturalpecking-order equilibrium, holding $G$ constant, an increase in the rent from holding office, $R$, induces the official to increase porkbarrel spending, to decrease the fraction of that spending that is efficient, and to decrease public good spending.

(ii) Suppose that $F$ and $H$ are uniform distributions. Then an increase in rent leads to an increase in the budget cap. In particular, elected officials are granted larger budgets than nonelected officials, ceteris paribus.

Proposition 4 (i) implies that if, for the same cap $G$, we consider two spending situations - one in which the election is imminent, the other in which it is still far off - we may expect the public official to undertake more pork-barrel spending, less public-good spending, and more off-balance-sheet spending in the former case. This is because, given discounting, the relative magnitude of $R$ (compared with the rest of the official's payoff) may be especially high

\footnotetext{
23 In practice, public good provision does have redistributive consequences, and thus there is a "continuum" between purely targeted spending (pork in our model) and untargeted spending (public good in our model).

24 Inefficient project choice here results from a desire to hide government liabilities, not from an intrinsic preference for inefficient projects. By contrast, the government in Robinson and Torvik (2005) deliberately and openly chooses inefficient projects ("white elephants") so as to enhance the chances of being re-elected. Efficient projects would be continued even if the challenger came to power while only the incumbent would pursue inefficient ones. Inefficiency then "forces" the interest group to vote for the incumbent.
}

just before an election. Of course, that $R$ is higher closer to an election is just an assumption conditioning this result. The standard justification (invoked in the political business cycle literature ${ }^{25}$ ) is that voters' memories are short. Another possibility is that the official's preferences follow a Markov process; ${ }^{26}$ incentives to signal are then higher closer to the election.

While obtained through functional form restrictions for tractability reasons, Proposition 4 (ii) seems robust and is new to the literature. The intuition is that, as $R$ increases, an elected official will spend more on pork, and so $G$ must increase to prevent worthwhile spending from being crowded-out and off-balance-sheet spending from increasing. For the same reasons, authorized spending should increase as an election nears.

The implication that ceteris paribus, accountable officials have larger budgets seems to be borne out by practice in democratic countries: Non-accountable officials have either relatively low budgets (antitrust, regulation) or budgets over which little discretion can be exercised (social security).

\section{Unknown spending propensity}

We have so far assumed that the official's overall spending propensity is common knowledge. Voters, however, may face uncertainty as to the desired spending level and not only its structure. When the electorate is uncertain about the level as well as the distribution of the official's spending priorities, an accountable official faces conflicting incentives: On the one hand, she wishes to seem congruent with as many individual interest groups as is consistent with reelection. On the other hand, she does not want the electorate to form the impression that she is a big spender.

We return to the simplified model of Section 3.1 and suppose that there are two types of officials: "Low spenders," in proportion $\rho$, favor a fraction $x_{L}$ of interest groups. "High spenders," in proportion $1-\rho$, favor a fraction $x=x_{H}>x_{L}$ of interest groups. Thus the expected pork-barrel intensity of a non-accountable official is

$y^{N A}=\bar{x}=(1-\rho) x_{H}+\rho x_{L}$.

As with known spending propensity, the spending propensities are derived from underlying distributions over weights. Namely, let $F_{H}(\alpha)$ and $F_{L}(\alpha)$ denote the cumulative distribution functions over weights $\alpha \in[0,+\infty)$, and $E_{H}($.$) and E_{L}($.$) the corresponding expecta-$ tion operators. As earlier we normalize expected weights to be equal to 1:

$E_{H}[\alpha]=E_{L}[\alpha]=1$,

and we will be interested in the case where $x_{L}$ and $x_{H}$ are less than $1 / 2$. The formal condition for $H$ types to be high spenders is for any cutoff weight generating pork level below $1 / 2$ for the low spender, the high spender spends more than the low spender:

$F_{H}(\alpha)<F_{L}(\alpha)$ for all $\alpha$ such that $1 / 2 \leq F_{L}(\alpha)<1$.

Letting $\alpha^{*} \equiv L / B$ (as before), we have

$x_{L}=1-F_{L}\left(\alpha^{*}\right)<x_{H}=1-F_{H}\left(\alpha^{*}\right)<1 / 2$

\footnotetext{
25 For example, Akhmedov and Zhuravskaya (2004) find strong evidence of political spending cycles in Russia in the period 1996-2003.

26 Fudenberg and Tirole (1995) build a theory of income and dividend smoothing on a similar assumption (there, managerial productivity or adequacy to the job varies according to a Markov process).
} 
Next, for $\theta \in\{L, H\}$ let

$U_{\theta}(y) \equiv\left[\int_{\alpha_{\theta}(y)}^{+\infty} \alpha d F_{\theta}(\alpha)\right] B-y L$

where

$1-F_{\theta}\left(\alpha_{\theta}(y)\right) \equiv y$

Note that utilities are concave in spending and that the high spender has a higher marginal demand for spending "in the relevant range" :

$\frac{\partial U_{H}(y)}{\partial y}-\frac{\partial U_{L}(y)}{\partial y}=\left[\alpha_{H}(y)-\alpha_{L}(y)\right] B>0$ for all $y$ such that $y \leq 1 / 2$

Finally, we assume that the rent from keeping office $R$ is the same for both types (this assumption is much stronger than needed), and that this rent from office satisfies condition (3) for both $\theta$ :

$U_{\theta}(1 / 2)+R>U_{\theta}\left(x_{\theta}\right)$ for $\theta \in\{L, H\}$

that is, under symmetric information about spending propensity, both types seek reelection by distributing more pork than they would wish to under non-accountability.

We consider two polar information structures: The date- 1 policy $\hat{\mathbf{y}}$ is transparent if each minority $j$ observes both $\hat{y}_{j}$ and $y$ before the date- 2 election. ${ }^{27}$ The date- 1 policy $\hat{\mathbf{y}}$ is non-transparent or opaque if each minority $j$ learns only the value of $\hat{y}_{j}$ before the date- 2 election. Non-transparency of course requires that the pork-barrel policy's cost be delayed. Indeed transparency and opaqueness are two polar cases of the accounting manipulation technology introduced in Section 4 . The policy is necessarily opaque if putting expenses offbalance sheet is costless $\left(D_{1}(1-\sigma)=1-\sigma\right)$ and transparent if it is infinitely costly $\left(D_{1}^{\prime}=+\infty\right)$.

We look for a natural-pecking-order equilibrium.

\subsection{Opaque policy}

To study representative democracy, let us first assume that the policy is opaque; that is, each interest group $j$ learns only whether it received a benefit $\left(\hat{y}_{j}=1\right)$ or not $\left(\hat{y}_{j}=0\right)$. Let $y_{H}$ and $y_{L}$ denote the equilibrium spendings (measures of interest groups receiving a benefit) of the high- and low-spenders. Let $\hat{x}_{1}$ and $\hat{x}_{0}$ denote a voter's expectations of $x_{\theta}$ conditional, respectively, on being and not being a spending beneficiary. Similarly, let $\hat{z}_{1}$ and $\hat{z}_{0}$ denote the probabilities of receiving date- 2 benefits if the official stays in office, conditional respectively on receiving and not receiving a first-period benefit.

We look for a pure-strategy perfect Bayesian equilibrium, and show that either the (natural-pecking-order) equilibrium is unique or there exists a second equilibrium. Let

$x^{+} \equiv \frac{E\left(x^{2}\right)}{E(x)}>E(x)=\bar{x}$

(where expectations are taken with respect to the prior belief $\rho$ ). $x^{+}$is the posterior mean of $x$ conditional on being a beneficiary when the official distributes benefits only to her favored groups $\left(y_{H}=x_{H}, y_{L}=x_{L}\right)$ at date 1 .

27 Given the focus on natural-pecking-order strategies, it does not matter whether the interest groups observe $y$ or the full $\hat{\mathbf{y}}$.
Similarly,

$x^{-} \equiv \frac{E[(1-x) x]}{1-\bar{x}}(<\bar{x})$

is the posterior mean of $x$ conditional on being a non-beneficiary. It is not hard to show that

$\frac{x^{+}-\bar{x}}{1-\bar{x}}=\frac{\bar{x}-x^{-}}{\bar{x}}$

Proposition 5 (Opaque policy). When the official's spending propensity is unknown and the policy is opaque, being a beneficiary carries both good news (one will be favored by the incumbent tomorrow) and bad news (the probability that the incumbent is a high spender has increased).

(i) A high-spending equilibrium, in which the politician builds a majority of interest groups by indicating her congruence with the latter $\left(y_{H}=y_{L}=1 / 2\right)$ always exists.

(ii) For generic payoffs this high-spending equilibrium is unique unless pork-barrel is sufficiently costly to the electorate $\left(B / L \leq\left(x^{+}-\bar{x}\right) /(1-\bar{x})\right)$, in which case a second, "Groucho Marx" equilibrium also exists. In the latter equilibrium, spending is as under a non-accountable official, and the politician is re-elected by non-beneficiaries. ${ }^{28}$

The Groucho Marx equilibrium, if it exists, is interesting in that it illustrates in a stark way the negative news conveyed by being a pork recipient: in situations of very low net benefit from pork, receiving pork can induce beneficiaries to vote against the incumbent, while non-beneficiaries vote for the incumbent, whom they perceive as a fiscal conservative. Nonetheless, we find this outcome empirically dubious, and in case of multiplicity, we will focus on the more natural equilibrium in which it is beneficiaries who vote for the incumbent.

Proof of Proposition 5. There are two sets of interest groups, spending beneficiaries and non-beneficiaries. There are therefore four possible voting patterns at the reelection stage:

a) Everyone votes for the official. This requires ${ }^{29}$

$$
\hat{z}_{1} B-\hat{x}_{1} L \geq \bar{x}(B-L)
$$

and

$$
\hat{z}_{0} B-\hat{x}_{0} L \geq \bar{x}(B-L),
$$

where $\hat{z}_{1}$ and $\hat{x}_{1}$ are the probabilities of being favored and expected pork in the second period conditional on being a beneficiary in the first period, and $\hat{z}_{0}$ and $\hat{x}_{0}$ are the corresponding variables conditional on not being a beneficiary. Because the official is re-elected regardless of her behavior, she selects her preferred action:

$$
y_{H}=x_{H} \quad \text { and } \quad y_{L}=x_{L} \text {. }
$$

\footnotetext{
28 This is reminiscent of Groucho Marx's famous remark: "I would never belong to a club that would admit me as a member."

29 Recall that we assume that when indifferent, the voter votes for the incumbent. We could alternatively assume that he votes for the challenger; this makes no difference.
} 
This implies

$$
\hat{z}_{1}=1, \quad \hat{z}_{0}=0, \quad \hat{x}_{1}=x^{+}, \quad \hat{x}_{0}=x^{-}
$$

And so, the two inequalities imply that

$$
B-x^{+} L \geq \bar{x}(B-L)
$$

and

$$
-x^{-} L \geq \bar{x}(B-L) \text {. }
$$

Rearranging, we obtain

$$
\frac{x^{+}-\bar{x}}{1-\bar{x}} \leq \frac{B}{L} \leq \frac{\bar{x}-x^{-}}{\bar{x}}
$$

But because the left- and right-hand sides of Eq. (8) are equal, this voting pattern can be an equilibrium configuration only in a knife-edge case.

b) Nobody votes for the official. Intuitively, in this configuration, beneficiaries are dissatisfied with the official because they infer that she is likely to be a high spender; non-beneficiaries are dissatisfied because they are not favored. Clearly, the official selects

$$
y_{H}=x_{H} \text { and } y_{L}=x_{L} \text {. }
$$

And so Eq. (7) holds. Thus for equilibrium we need:

$$
B-x^{+} L<\bar{x}(B-L) \text { and }-x^{-} L<\bar{x}(B-L) .
$$

Rearranging, we obtain

$$
\frac{\bar{x}-x^{-}}{\bar{x}}<\frac{B}{L}<\frac{x^{+}-\bar{x}}{1-\bar{x}}
$$

which, since the left- and right-hand sides are equal, is impossible.

c) Only beneficiaries vote for the official. This voting pattern corresponds to

$$
\hat{z}_{1} B-\hat{x}_{1} L \geq \bar{x}(B-L)
$$

and

$$
\hat{z}_{0} B-\hat{x}_{0} L<\bar{x}(B-L)
$$

And thus

$$
y_{H}=y_{L}=1 / 2, \quad \hat{z}_{1}=2 \bar{x}, \quad \hat{z}_{0}=0, \quad \hat{x}_{1}=\hat{x}_{0}=\bar{x} .
$$

The voter learns nothing about the official's aggregate spending preferences, and the two inequalities hold for all values of the parameters.

d) Only non-beneficiaries vote for official (Groucho Marx equilibrium). In this voting pattern, beneficiaries do not vote for an official who favored them as this is a bad signal about her aggregate spending propensity, $\hat{x}_{1}=x^{+}>\bar{x}$, but nonbeneficiaries (who perceive average spending propensity to be $\hat{x}_{0}=x^{-}<\bar{x}$ ) do. The official then gets re-elected and favors her preferred groups $\left(y_{\theta}=x_{\theta}\right)$, and equilibrium obtains if and only if

$$
B-x^{+} L<\bar{x}(B-L)
$$

and

$$
-\chi^{-} L \geq \bar{x}(B-L)
$$

that is, if and only if

$$
\frac{B}{L}<\frac{x^{+}-\bar{x}}{1-\bar{x}} \equiv \frac{\bar{x}-x^{-}}{\bar{x}}
$$

\subsection{Transparency}

Consider now the polar case in which interest groups observe not only what they receive but also the total spending $y$ by the politician. The same countervailing incentives under an opaque system are still in play. The official would like to convince individual interest groups that she is willing to spend for them, while at the same time appearing to be a low spender. But we would expect the latter incentive to be stronger under transparency and so transparency to induce more restraint.

The signaling game under transparency has many equilibria, and we will content ourselves with a study of equilibria satisfying D1. In case of multiplicity of such equilibria, we will use Pareto dominance to single out a unique one. Let $p(y)$ denote the probability of reelection when aggregate spending is $y$.

Assume that

$U_{H}\left(x_{L}\right)+R>U_{H}\left(x_{H}\right)$

(The electoral concern is strong enough to induce a high spender to choose the low spender's preferred spending level if that will get her re-elected) and

$U_{\theta}(0)+R<U_{\theta}\left(x_{\theta}\right)$ for all $\theta$

(The electoral concern is not strong enough to induce an official to forego current pork-barrel spending altogether).

Finally, let

$b_{1} \equiv \rho\left[\frac{x_{H}-x_{L}}{(1+\rho) x_{H}-\rho x_{L}}\right]$ and $b_{2}\left(y_{L}\right) \equiv(1-\rho)\left[\frac{x_{H}-x_{L}}{\rho x_{L}+(1-\rho) x_{H}-\frac{x_{L}-y_{L}}{1-y_{L}}}\right]$.

Let $y_{L}^{*}$ and $y_{L}^{* *}$, with $y_{L}^{*}<y_{L}^{* *} \leq x_{L}$ be defined by:

$U_{H}\left(x_{H}\right) \equiv U_{H}\left(y_{L}^{*}\right)+R$

and

$y_{L}^{* *} \equiv\left\{\begin{array}{l}x_{L}, \text { if } \quad U_{H}(1 / 2) \geq U_{H}\left(x_{L}\right) \\ y, \text { where } U_{H}(1 / 2)=U_{H}(y) \text { and } y<x_{L}, \text { if } U_{H}(1 / 2)<U_{H}\left(x_{L}\right) .\end{array}\right.$

Any Pareto optimal equilibrium outcome either coincides with the standard equilibrium outcome under opaqueness or involves less spending (for each type) than in that equilibrium. Indeed, for some parameter values, there are equilibria in which spending is below that of a non-accountable official. 
Proposition 6 (Transparency). Assume beliefs satisfy the naturalpecking-order assumption. When the official's spending propensity is unknown and the policy is transparent, the politician faces a dilemma between indicating congruence with individual interest groups and signaling a low overall spending propensity. The equilibrium satisfying D1 and Pareto dominance is unique and exhibits even more restraint than under a non-accountable official when pork is socially very costly. The high spender is not reelected, $y_{H}=x_{H}$ and $y_{L}=y_{L}^{*}<x_{L}$ if $B / L \leq$ $\min \left\{b_{1}, b_{2}\left(y_{L}^{*}\right)\right\}$. If $b_{1} \leq B / L \leq b_{2}\left(y_{L}^{* *}\right)$, the equilibrium is separating with $y_{H}=1 / 2$ and $y_{L}=\min \left\{x_{L}, y_{L}^{* *}\right\}$; both the high and the low spenders are reelected. If $b_{2}\left(x_{L}\right) \leq B / L \leq b_{1}$, then $y_{\theta}=x_{\theta}$ for $\theta \in\{L, H\}$, and the official always being voted out of power is an equilibrium. Finally, if pork is not very costly $\left(B / L \geq b_{2}\left(x_{L}\right)\right)$, the equilibrium is the same, higher-spending equilibrium as under known spending propensity.

Proof. We look in turn for separating equilibria in which (a) only the low type is reelected, (b) the official is never reelected and (c) both types are reelected. We then look for a pooling equilibrium, in which both types are necessarily reelected.

1. Separating equilibrium in which the low but not the high type is re-elected. In this case, the high type may as well choose her static bliss point:

$$
y_{H}=x_{H} .
$$

Furthermore, from Eq. (6), it must be the case that an official known to be a high spender is not able to assemble a minimal majority of beneficiaries to re-elect her: ${ }^{30}$

$$
\left(2 x_{H}\right) B-x_{H} L \leq \bar{x}(B-L) \Longleftrightarrow b_{1} \equiv \rho\left[\frac{x_{H}-x_{L}}{(1+\rho) x_{H}-\rho x_{L}}\right] \geq \frac{B}{L}
$$

If the low type must assemble a majority to be reelected, then Eq. (6) implies the high type has the incentive to imitate. Hence, in equilibrium, the low type must be voted for not only by beneficiaries, but also by non-beneficiaries. A non-beneficiary still has probability $\left[x_{L}-y_{L}\right] /\left[1-y_{L}\right]$ of being in the official's favored list. So unanimous reelection requires that:

$$
\begin{aligned}
& \left(\frac{x_{L}-y_{L}}{1-y_{L}}\right) B-x_{L} L \geq \bar{x}(B-L) \Longleftrightarrow b_{2}\left(y_{L}\right) \\
& \quad \equiv(1-\rho)\left[\frac{x_{H}-x_{L}}{\rho x_{L}+(1-\rho) x_{H}-\frac{x_{L}-y_{L}}{1-y_{L}}}\right] \geq \frac{B}{L}
\end{aligned}
$$

In equilibrium, we cannot have $y_{L}=x_{L}$, otherwise, from Eq. (9) the high spender would want to mimic the low spender. The separating equilibrium satisfying the intuitive criterion thus involves

$$
y_{L}=y_{L}^{*}<x_{L},
$$

with

$$
U_{H}\left(x_{H}\right)=U_{H}\left(y_{L}^{*}\right)+R \text {. }
$$

\footnotetext{
30 Note that if the high type deviates to $y=1 / 2$, the worst possible beliefs are that she is believed to be a high type. Furthermore, the natural-pecking-order assumption implies that a beneficiary believes he has probability $2 x_{H}$ of being among those favored by the high type. So condition (11) is a necessary and sufficient condition, for the high type not wanting to deviate.
}

To see this, note that, from Eqs. (9) and (10), there exists $y_{L}^{*}$ satisfying Eq. (13). Furthermore,

$$
\frac{\partial U_{H}}{\partial y}(y)>\frac{\partial U_{L}}{\partial y}(y)
$$

implies

$$
U_{H}\left(x_{H}\right)-U_{H}\left(y_{L}^{*}\right)>U_{L}\left(x_{H}\right)-U_{L}\left(y_{L}^{*}\right)
$$

and so Eq. (13) and $x_{H}>x_{L}$ imply

$$
U_{L}\left(x_{L}\right)<U_{L}\left(y_{L}^{*}\right)+R
$$

Hence, the configuration $\left(y_{L}, y_{H}\right)=\left(y_{L}^{*}, x_{H}\right)$ constitutes a separating equilibrium if $B / L \leq \min \left\{b_{1}, b_{2}\left(y_{L}^{*}\right)\right\}$, and because $y_{L}^{*}$ is the smallest deviation from $x_{L}$ that satisfies the high type's incentive constraint, the equilibrium satisfies D1. In this case, transparency induces restraint. ${ }^{31}$

2. Separating equilibrium in which no type is reelected. In the absence of reelection, $y_{L}=x_{L}$ and $y_{H}=x_{H}$. This requires that Eq. (11) be satisfied (for the same reason as in Footnote 30) and that the low type not be reelected when choosing $y_{L}=x_{L}$. So, this equilibrium exists when

$$
b_{2}\left(x_{L}\right) \leq \frac{B}{L} \leq b_{1} .
$$

3. Separating equilibrium in which both types are re-elected. In this configuration $y_{H}=1 / 2$, and Eq. (11) must be violated while Eq. (12) is satisfied for whatever $y_{L} \leq x_{L}$ is picked by the low spender. In this case,

$$
y_{L}^{* *}=x_{L} \quad \text { if } \quad U_{H}(1 / 2) \geq U_{H}\left(x_{L}\right)
$$

and

$$
y_{L}^{* *}<x_{L} \quad \text { if } \quad U_{H}(1 / 2)=U_{H}\left(y_{L}^{* *}\right)<U_{H}\left(x_{L}\right)
$$

Hence, this universal reelection equilibrium requires that $b_{1} \leq B / L \leq b_{2}\left(y_{L}^{* *}\right)$.

4. Pooling equilibria. Finally, a pooling equilibrium with universal reelection requires building up a majority, so

$$
y_{L}=y_{H}=y^{o} \geq 1 / 2 \quad \text { and } \quad U_{L}\left(y^{o}\right)+R \geq U_{L}\left(x_{L}\right)
$$

and yields the high-spending outcome of Section 5.1. For this to be an equilibrium, it must be the case that setting $y_{L}=x_{L}$ does not get the low-type re-elected, i.e., Eq. (12) for $y_{L}=x_{L}$, or $b_{2}\left(x_{L}\right) \geq B / L$ is violated. Conversely $b_{2}\left(x_{L}\right) \leq B / L$ suffices to construct a pooling equilibrium.

Ranking of equilibrium payoffs. Let us compare the four types of equilibria: 1 . separating, reelection of low spender; 2 . separating, no reelection; 3 . separating, universal reelection; 4. pooling, universal reelection.

Note first that the type-2 equilibrium is always dominated for the official by the type- 1 equilibrium. Next, an equilibrium of type 1 is dominated by equilibria of type 3 and 4 . The high spender receives $U_{H}\left(x_{H}\right)$, which she can guarantee herself in any equilibrium. The low

\footnotetext{
31 More generally, in any separating equilibrium in which the high type is not elected there is less pork-barrel than under a non-accountable official.
} 
type receives $U_{L}\left(y_{L}^{*}\right)+R$, against the larger $U_{L}\left(y_{L}^{* *}\right)+R$ in a type3 equilibrium and against $U_{L}(1 / 2)+R$ in a type-4 equilibrium. In the latter equilibrium, selecting $y_{L}^{*}$ would from D1 be interpreted as coming from type $L$ and guarantee reelection whenever a type1 equilibrium also exists. Finally, a type- 3 equilibrium dominates a type-4 equilibrium when they co-exist. The high spender receives $U_{H}(1 / 2)+R$ in both. The low spender receives in a type- 3 equilibrium $U_{L}\left(y_{L}^{* *}\right)+R \geq U_{L}(1 / 2)+R$ whenever a type-3 equilibrium exists.

\subsubsection{Comparison}

If we rule out, as we did, the Groucho Marx equilibrium in the opaque case, transparency is always (at least weakly) conducive to restraint. However, the analysis of Section 4 would still apply if we added socially desirable public spending and/or time-shifting ability. Transparency would then induce the official to cut down on desirable public spending and to increase the cost of public spending through off-balance-sheet liabilities. While opaque policies never lead to off-balance-sheet financing and curtailment of efficient public goods, transparency incentivizes such behaviors. This of course does not provide a strong argument for opacity; rather it says that a particular attention to off-balance-sheet manipulations and transparency concerning public good provision is called for when imposing a spending cap or promoting transparency of the overall level of spending.

\subsubsection{Empirical evidence}

This analysis speaks to the current debate about the impact on the probability of reelection of austerity and more broadly reforms (which, like pork barrel, have both efficiency and redistributive consequences). Drazen and Eslava (2010) find evidence that voters react positively to pork and negatively to overall spending, in conformity with this paper's analysis. Brender and Drazen (2008), looking at 74 democracies, find that an increase in public deficit in an election year does not increase the probability of reelection; it actually decreases it in established democracies (as it does at the state or local level in the studies of Peltzman, 1992; Brender, 2003; Drazen and Eslava, 2010). More casually, politicians who in the recent past have conducted large scale reforms of the State and/or the labor market were either reelected (Australia, Canada and Sweden) or voted out (Germany). Obviously further empirical work in the area would be very useful. From the analysis, we know that whether in the end pork allows the official to be reelected, an official who opts for a small level of spending really wants to let this be known to the electorate.

\subsubsection{Beyond opaque and transparent policies}

If there is a probability between 0 and 1 that total spending is revealed to the public, spending behavior is weakly decreasing in the level of transparency.

\section{Summary and discussion}

This paper offers a complementary approach to the wellestablished and useful "grabbing" theories of budget deficit. Our "pandering" approach captures the idea that politicians like to signal that they stand for individual groups' interest or share their identity, while being fiscal conservatives overall. Besides adding realism, pandering also allows us to study issues, such as transparency and offbalance sheet activities, that are intrinsically linked to informational asymmetries between rulers and voters.

In the model, voters who receive benefits from political incumbents are more likely to re-elect these incumbents because they truly learn something about the incumbents' stance toward them. This gives the politicians in office an incentive to distribute pork to constituencies, and generates excessive public spending.
A spending cap, such as those prevailing in the European Union or many American states, curbs pork, but also reduces the provision of public goods, and furthermore encourages politicians to shift expenditures off-balance-sheet, at the cost of increased total spending. The optimal cap should be looser for an accountable official, especially in years just prior to elections.

The desire to appear fiscally conservative provides a countervailing incentive for politicians to limit pork. Even if expenses can be shifted off-balance-sheet and so total expenses are unobserved, receiving pork suggests that the politician is a high spender. A greater transparency of public expenditure reduces pork.

In our view, an important open research area in public finance, macroeconomics and industrial organization is that of public accounting. Like in the private sector, and perhaps more so because of the absence of stock market values, accounting is key to accountability. While a substantial policy literature has studied the European Stability Pact and various other fiscal rules, little research has been directed toward a theory of public accounting. ${ }^{32}$

\section{Appendix A}

\section{A.1. Uniqueness of equilibrium in the opaque case}

Proposition 1A. In the opaque case, there is a unique PBE, which is the unique natural-pecking-order equilibrium (and for which $y=1 / 2$ ).

Proof. We prove the result via three claims.

Claim 1. In a PBE, the official gets reelected regardless of her type.

Proof of claim. Suppose type $\omega$ does not get reelected in equilibrium. Then she must be choosing a natural-pecking-order policy with $y=x$, and every interest group that gets pork votes for her reelection. Hence, for any out-of-equilibrium policy, any interest group that gets pork must vote for reelection. Hence, if she chooses the natural-pecking-order policy with $y=1 / 2$, she will be reelected and, from Eq. (3), will be better off, a contradiction.

\section{Claim 2. In a PBE, every $x$-favored interest group is offered pork.}

Proof of claim. If, for type $\omega$, some $x$-favored group is not offered pork, the type $\omega$ official can improve her payoff by offering it, a contradiction.

Notice that in view of Claim 2, any interest group that is offered pork cannot distinguish between an equilibrium and an out-ofequilibrium policy.

Claim 3. In a PBE (or in response to any out-of-equilibrium policy), any group that is offered pork votes for reelection.

Proof of claim. Suppose some group $j$ that is offered pork votes against reelection. Group $j$ has an ex-ante probability $x$ of being $x$-favored, in which case (from Claim 2) it would be offered pork in equilibrium. So, for it to be an undominated strategy for $j$ to vote against reelection, $j$ must be offered pork with probability 1

\footnotetext{
32 Maskin and Tirole (2007) touch on the public accounting treatment in a very specific context, that of public procurement, and argues that cost-plus contracts are vulnerable to a new form of adverse selection, as politicians may strategically award such contracts for "white elephant" projects. It further shows how private financing of high-powered incentives schemes may help "securitize" (make more transparent) public debt.
} 
in equilibrium. In particular, $j$ must be offered pork when not $x$ favored. But then the official would be better off not offering $j$ pork, a contradiction.

In view of Claims 1 and 3, it is optimal for the official to offer pork to an interest group if and only if it is $1 / 2$-favored.

\section{A.2. Uniqueness of equilibrium in the transparent case}

Proposition 1B. In the transparent case, the unique PBE satisfying D1 is the natural-pecking-order equilibrium with $y=1 / 2$ (assuming indivisible pork).

Proposition 1C (Divisible pork). When pork is divisible and in the transparent case, and focusing on equilibria that satisfy D1,

(i) the indivisible-pork equilibrium is still the unique equilibrium if

$$
K \equiv \int_{1 / 2}^{1-[x / 2(1-x)]}\left(\alpha^{i}-\alpha^{1-x}\right) d i \geq 0
$$

(ii) if $K<0$ (as is the case for affine $\alpha^{i}$ ), this equilibrium is no longer unique; it yields the official's lowest utility among equilibria satisfying D1. All equilibria involve a reelection by a majority of one half of the voters, but some may receive little pork.

Proof. We first note that, whether symmetric or not, whether pork is divisible or not, the incumbent's equilibrium utility is, under D1, at least equal to $U(1 / 2)+R$. Suppose it were not, and let $U^{*}(\omega)$ denote the equilibrium utility of type $\omega$ and $\omega_{0} \equiv \arg \inf U^{*}(\omega)$. Consider the policy $\hat{\mathbf{y}}\left(\omega_{0}\right)$ consisting in giving pork $\hat{y}_{j}=1$ to interest groups ranked by $\omega_{0}$ above $1 / 2$ (i.e. according to $\omega_{0}$ 's natural peking order). So $\mathbf{U}\left(\hat{\mathbf{y}}\left(\omega_{0}\right), \omega_{0}\right)=U(1 / 2)>\mathbf{U}\left(\hat{\mathbf{y}}\left(\omega_{0}\right), \omega\right)$ for all $\omega$ whose preferences differ from those of $\omega_{0}$ on a set of strictly positive measure. Let

$\mathcal{P}\left(\hat{\mathbf{y}}\left(\omega_{0}\right), \omega\right)=\left\{p \mid U^{*}(\omega)<\mathbf{U}\left(\hat{\mathbf{y}}\left(\omega_{0}\right), \omega\right)+p R\right\}$

The set $\mathcal{P}$ is larger for $\omega_{0}$ than for any other $\omega$ (except those "equivalent types" satisfying $U^{*}(\omega)=U^{*}\left(\omega_{0}\right)$ and differing from $\omega_{0}$ only on a set of measure 0$)$. Thus following $\hat{y}_{j}\left(\omega_{0}\right)=1$, interest group $j$ should vote for the incumbent, who therefore will be reelected. So $U^{*}(\omega) \geq U(1 / 2)+R$ for all $\omega$. But the only policy that attains payoff $U(1 / 2)+R$ is the natural-pecking-order policy with $y=1 / 2$.

When pork is divisible, the upper bound on payoff is again $U(1 / 2)+R$ iff

$K \equiv \int_{\frac{1}{2}}^{1-\frac{x}{2(1-x)}}\left(\alpha^{i}-\alpha^{1-x}\right) d i \geq 0$.

Furthermore, the upper bound, which is also the lower bound, can be implemented only by giving pork to the $50 \%$ preferred groups. But $K$ may be negative. For example, for affine $\alpha^{i}$

$K=\int_{\frac{1}{2}}^{1-\frac{x}{2(1-x)}}[i-(1-x)] d i<0$

with strict inequality unless $x=1 / 2$.
If $K<0$, the upper bound is reached through

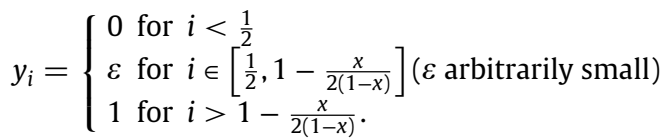

Note that this two-pork-level outcome can only be an equilibrium if $\hat{\mathbf{y}}$ is observed by interest groups, and not just $\hat{y}_{k}$. Otherwise, the official would deviate to picking $y_{i}=1$ for $i \geq 1-x$.

\section{A.3. Direct democracy}

Suppose that the status quo involves no perk for anyone, that a majority of votes in favor of an allocation $\hat{\mathbf{y}}$ is required to overcome the status quo, and that all allocations are on the ballot ${ }^{33}$. Consider an equilibrium outcome $\hat{\mathbf{y}}^{*}$. Let $W^{*} \equiv\left\{j \mid \hat{y}_{j}^{*} B-\hat{y}^{*} L>0\right\}$ denote the set of winners relative to the status quo, and $w^{*}$ its weight (i.e. the fraction of winners). We look for a coalition-proof equilibrium.

Suppose, first, that $w^{*}<1 / 2$. Then a coalition of size $1 / 2$ among non-winners (interest groups not in $W^{*}$ ) could vote for another allocation giving pork 1 to its members and pork 0 to everyone else. This coalition would gain provided that $B>L / 2$.

So assume that $w^{*} \geq 1 / 2$. If $w^{*}>1 / 2$, any sub-coalition of size $1 / 2$ would benefit strictly from voting for an allocation $\hat{\mathbf{y}}$ giving the same pork to its members and no pork to non-coalition members.

\section{A.4. Proof of Proposition2}

In a generalized natural-pecking-order equilibrium, the incumbent is re-elected if and only if

$$
\int v_{i} y_{i} d i+(1-v) \phi \geq \int v_{i}\left(1-y_{i}\right) d i+(1-v)(1-\phi),{ }^{34}
$$

where $v \equiv \int v_{i} d i$. And so

$p(y) \equiv 1-H\left(\frac{1}{2}+\frac{\int v_{i}\left(1-2 y_{i}\right) d i}{2(1-v)}\right)$.

The official's optimal policy solves

$\max _{y}\{U(y)+p(y) R\}$

where

$U(y) \equiv \int \alpha^{i}\left(y_{i} B-y L\right) d i$

Thus, interest group of rank $i$ receives pork $\left(y_{i}=1\right)$ if and only if

$\alpha^{i} B+\frac{h}{1-v} v_{i} R \geq L$

Interest group $j$, when receiving pork, knows that $\alpha^{\omega(j)} \geq$ $\max \left\{0, \frac{L-\frac{h}{1-v} v_{j} R}{B}\right\}$ and so votes for the incumbent. And conversely when interest group $j$ does not receive pork.

From Eq. (A1), an interest group's ability to attract pork depends not only on how favored it is (i.e., on $\alpha^{\omega(j)}$ ), but also on how

\footnotetext{
33 Alternatively, one could consider a citizen candidate model as in Osborne and Slivinski (1996) and Besley and Coate (1997).

34 We assume that the ideological vote can push the election one way or the other (that is, we rule out corner solutions). If $v_{j}=v$ for all $j$, this implies that $v \leq 1 / 2$.
} 
pocketbook-oriented it is (i.e., on $v_{j}$ ). ${ }^{35}$ Its prospects for pork improve with a local increase in $h$, which implies that the probability of victory is more responsive to a small swing in voting. That is, the interest group is more likely to receive pork if the election is hotly contested. Finally, pork will also increase with $R$; the official will be willing to spend more, the higher the value she attaches to office.

Finally, consider uniqueness. Consider two generalized naturalpecking-order equilibria with total spending $y$ and $\tilde{y}$, where $y>\tilde{y}$, or equivalently from Eq. (A1) $h>\tilde{h}$. This also implies that $\left\{i \mid \tilde{y}_{i}=1\right\} \subset$ $\left\{i \mid y_{i}=1\right\}$, which in turn implies, together with the density being non-decreasing that $h \leq \tilde{h}$, a contradiction.

\section{A.5. Proof of Proposition 3}

The first-order conditions for $\sigma$ and $g$ are:

$D_{1}^{\prime}(1-\sigma)=D_{2}^{\prime}\left(g_{0}-g\right)=1+\mu$

where $\mu$ is the Lagrange multiplier for Eq. (5). The first-order condition with respect to $y_{i}$ is:

$$
\begin{aligned}
y_{i} & =1 \Longleftrightarrow \alpha^{i} B+\frac{h v}{1-v} R \geq\left[\sigma+D_{1}(1-\sigma)+\mu \sigma\right] L \\
& =\left[D_{1}(1-\sigma)+\sigma D_{1}^{\prime}(1-\sigma)\right] L
\end{aligned}
$$

If the spending cap $G$ is increases, then $\mu$ decreases. Thus from Eq. (A2), $\sigma$ and $g$ increase. That is,

$$
\frac{d \sigma}{d G}>0 \text { and } \frac{d g}{d G}>0
$$

Now, the derivative of the right-hand side of the inequality in Eq. (A3) is

$-\sigma D_{1}^{\prime \prime} \frac{d \sigma}{d G} L<0$

The derivative of the left-hand side of Eq. (A3) taken at the cutoff $\alpha(y)$ so as to make Eq. (A3) an equality is $\left[\frac{d \alpha}{d y} B-\left(\frac{v}{1-v}\right)^{2} h^{\prime} R\right] \frac{d y}{d G}$. Hence because $h^{\prime} \geq 0$ and $d \alpha / d y<0$,

$\frac{d y}{d G}>0$.

\section{A.6. Proof of Proposition4}

(i) From Eq. (5) we can replace $g$ in Eq. (4) with $G-L y \sigma$ resulting in objective function

$$
\begin{aligned}
\max _{\mathbf{y}, \sigma}\left\{\int \alpha^{i} y_{i} B d i-y L\left[\sigma+D_{1}(1-\sigma)\right]-[G-\sigma y L]\right. \\
\left.+W-D_{2}\left(g_{0}-G+\sigma y L\right)+\left[1-H\left(\frac{1-2 v y}{2(1-v)}\right)\right] R\right\}
\end{aligned}
$$

We thus obtain first-order conditions for $\sigma$ and $y_{i}$ :

$$
D_{1}^{\prime}(1-\sigma)=D_{2}^{\prime}\left(g_{0}-G+\sigma y L\right)
$$

\footnotetext{
35 Notice that if $v_{j}$ is sufficiently low, an interest group $j$ receives pork only if $\alpha_{\omega(j)} B>$ $L$ and so when the $v_{j}$ 's are low, less than a majority of interests groups get pork.
}

and

$$
\begin{aligned}
y_{i} & =1 \Longleftrightarrow \alpha^{i} B-D_{1}(1-\sigma) L-D_{2}^{\prime}\left(g_{0}-G+\sigma y L\right) \sigma L \\
& +\frac{h v}{1-v} R \geq 0 .
\end{aligned}
$$

Consider how the optimal values of $\sigma$ and $y$ depend on the rent $R$. Differentiating Eq. (A5) with respect to $R$, we obtain $^{36}$

$$
-D_{1}^{\prime \prime} \frac{d \sigma}{d R}-D_{2}^{\prime \prime}\left(y \frac{d \sigma}{d R}+\sigma \frac{d y}{d R}\right) L=0
$$

Suppose first that

$$
\frac{d \sigma}{d R}<0
$$

Then, Eqs. (A7) and (A8) imply that

$$
\frac{d y}{d R}>0 \text {. }
$$

Next suppose that

$$
\frac{d \sigma}{d R}>0
$$

Differentiating the left-hand side of the inequality in Eq. (A6) with respect to $R$ and using Eq. (A5), we obtain

$$
-\sigma D_{2}^{\prime \prime}\left(y \frac{d \sigma}{d R}+\sigma \frac{d y}{d R}\right) L+\frac{h v}{1-v}
$$

which from Eq. (A7) can be rewritten as

$$
\sigma D_{1}^{\prime \prime} \frac{d \sigma}{d R}+\frac{h v}{1-v}
$$

which, from Eq. (A10), is positive. So, once again, we infer that Eq. (A9) holds. Now, if Eq. (A10) holds, then Eq. (A9) implies that Eq. (A7) can't hold. Hence Eq. (A8) must hold (i.e., the efficiency of spending declines), Eqs. (A7) and (A8) imply that $\frac{d}{d R}(y \sigma)>0$, and hence $\frac{d g}{d R}<0$.

36 Alternatively, one can differentiate the LHS of Eq. (A6) taken at the cutoff $\alpha(y)$. This would yield (after some manipulations)

$$
B \frac{d \alpha}{d y} \frac{d y}{d R}-\sigma D_{2}^{\prime \prime}\left(y \frac{d \sigma}{d R}+\sigma \frac{d y}{d R}\right) L+\frac{h v}{1-v}=0, \quad \text { where } \quad \frac{d \alpha}{d y}=-\frac{1}{f(y)}<0,
$$

and so 
(ii) Behind the veil of ignorance, pork distributed at date 2 and officials' rents in the two periods are constant. Date- 1 welfare $^{37}$ is

$$
W=y\left[B-L\left[\sigma+D_{1}(1-\sigma)\right]\right]-g+B_{0}-D_{2}\left(g_{0}-g\right)
$$

where

$$
y=1-F\left[\frac{\left[\sigma+D_{1}(1-\sigma)+\mu \sigma\right] L-\frac{h v}{1-v} R}{B}\right] .
$$

$W$ can be written as

$$
W=\left[B_{0}-y(L-B)-g_{0}\right]-\phi(y, \mu)
$$

where the deadweight loss from manipulations, $y L\left[D_{1}(1-\sigma)-(1-\sigma)\right]+D_{2}\left(g_{0}-g\right)-\left(g_{0}-g\right)$, can be written

$$
\phi(y, \mu)=y N(\mu)+M(\mu)
$$

where $N$ and $M$ are increasing functions of $\mu$. Let us assume that the distributions $F$ and $H$ are uniform. Then

$$
y=y(\mu, R)=\xi-\beta\left[\mu \sigma(\mu)+\sigma(\mu)+D_{1}(1-\sigma(\mu))\right]+\gamma R
$$

for some positive coefficients $\{\alpha, \beta, \gamma\}$.

And so:

$$
\begin{aligned}
& W(\mu, R)=B_{0}-[L-B+N(\mu)]\left[\xi-\beta\left[\sigma+D_{1}(1-\sigma)+\mu \sigma\right]+\gamma R\right] \\
& \quad-g_{0}-M(\mu) .
\end{aligned}
$$

Note that $\partial^{2} W / \partial \mu \partial R<0$, and so the optimal $\mu$ decreases with $R$ : accounting manipulations are costlier when pork barrel is high, i.e., when reelection concerns are important; $g$ therefore increases with $R$. As for $y$, and using Eq. (A2)

$$
\frac{d y}{d R}=\gamma-\beta \frac{d \mu}{d R} \sigma>0
$$

Finally,

$$
\frac{d G}{d R} \equiv \frac{d g}{d R}+L y \frac{d \sigma}{d R}+L \frac{d y}{d R} \sigma>0 .
$$

The cap increases with career concerns for essentially two reasons. First, it needs to accommodate the increase in pork $(d y / d R>0)$. Second, because this increase makes manipulations more costly, the budget constraint must be relaxed and so $g$ and $\sigma$ increase.

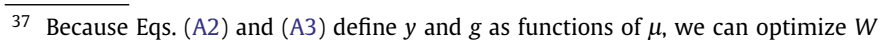
with respect to $\mu$ :

$$
\mu\left[\frac{y L}{\overline{D_{1}^{\prime \prime}}}+\frac{1}{\overline{D_{2}^{\prime \prime}}}\right]=\frac{\left[L\left(\sigma+D_{1}\right)-B\right]}{\left[1+h^{\prime}\left(\frac{v}{1-v}\right)^{2} \frac{f R}{B}\right]} f \frac{\sigma}{B} L,
$$

where $f$ is the density of $F$.

\section{References}

Aghion, P., Bolton, P., 1990. Government domestic debt and the risk of default: a political-economic model of the strategic role of debt. In: Dornbusch, R., Draghi, M. (Eds.), Capital Markets and Debt Management. MIT Press, Cambridge, MA.

Akhmedov, A., Zhuravskaya, E., 2004. Opportunistic political cycles: test in a young democracy setting. Q. J. Econ. 1301-1339.

Alesina, A., Tabellini, G., 1990. A positive theory of fiscal deficits and government debt Rev. Econ. Stud. 57, 403-414. https://doi.org/10.2307/2298021.

Alesina, A., Tabellini, G., 2007. Bureaucrats or politicians? Part I: a single policy task. Am. Econ. Rev. 97 (1), 169-179. https://doi.org/10.1257/aer.97.1.169.

Alesina, A., Tabellini, G., 2008. Bureaucrats or politicians? Part II. J. Public Econ. 92, 426-447. https://doi.org/10.1016/j.jpubeco.2007.06.004.

Banks, J., Sobel, J., 1987. Equilibrium selection in signaling games. Econometrica 55 (3), 647-661. https://doi.org/10.2307/1913604.

Battaglini, M., Coate, S., 2007. Inefficiency in legislative policy-making: a dynamic ana1ysis. Am. Econ. Rev. 97, 118-149. https://doi.org/10.1257/aer.97.1.118.

Battaglini, M., Coate, S., 2008. A dynamic theory of public spending, taxation and debt. Am. Econ. Rev. 98 (1), 201-236. https://doi.org/10.1257/aer.98.1.201.

Bennedsen, M., Feldmann, S., 2002. Lobbying legislatures. J. Polit. Econ. 110 (4), 919 946. https://doi.org/10.1086/340775.

Bennedsen, M., Feldmann, S., 2006. Informational lobbying and political contributions. J. Public Econ. 90 (4-5), 631-656. https://doi.org/10.1016/j.jpubeco.2005.08.003.

Bernheim, D., Peleg, B., Whinston, M., 1987. Coalition-proof Nash equilibria I. Concepts. J. Econ. Theory 42 (1), 1-12. https://doi.org/10.1016/00220531(87)90099-8.

Besley, T., Coate, S., 1997. An economic model of representative democracy. Q. J. Econ. 112 (1), 85-114. https://doi.org/10.1162/003355397555136.

Brender, A., 2003. The effect of fiscal performance on local government election results in Israel: 1989-1998. J. Public Econ. 87 (9-10), 2187-2205.

Brender, A., Drazen, A., 2008. How do budget deficits and economic growth affect reelection prospects? Evidence from a large panel of countries. Am. Econ. Rev. 98 (5), 2203-2220. https://doi.org/10.1257/aer.98.5.2203.

Brender, A., Drazen, A., 2013. Elections, leaders, and the composition of government spending. J. Public Econ. 97, 18-31. https://doi.org/10.1016/j.jpubeco.2012.08. 011.

Calmfors, L., 2005. What remains of the stability pact and what next? Swedish Institute for European Policy Studies, 8. http://www.iies.su.se/lcalmfor.

Canes-Wrone, B., Herron, M., Shotts, K., 2001. Leadership and pandering: a theory of executive policymaking. Am. J. Polit. Sci. 45 (3), 532-550. https://doi.org/10.2307/ 2669237.

Coate, S., 2004. Political competition with campaign contributions and informative advertising. J. Eur. Econ. Assoc. 2, 772-804.

Cox, G., McCubbins, M., 1986. Electoral politics as a redistributive game. J. Polit. 48 (02), 370-389. https://doi.org/10.2307/2131098.

Dewatripont, M., Jewitt, I., Tirole, J., 1999. The economics of career concerns. II: applications to missions in organizations. Rev. Econ. Stud. 66 (1), 199-217. https://doi. org/10.1111/1467-937X.00085.

Dewatripont, M., Seabright, P., 2006. 'Wasteful' public spending and state aid control. J. Eur. Econ. Assoc. 4 (2-3), 513-522. https://doi.org/10.1162/jeea.2006.4.2-3. 513.

Dixit, A., 1996. The Making of Economic Policy. MIT Press.

Dixit, A., Londregan, J., 1996. The determinants of success of special interests in redis tributive politics. J. Polit. 58 (4), 1132-1155. https://doi.org/10.2307/2960152.

Dixit, A., Londregan, J., 1998. Ideology, tactics, and efficiency in redistributive politics. Q. J. Econ. 113 (2), 497-529. https://doi.org/10.1162/003355398555667.

Drazen, A., Eslava, M., 2006. Pork barrel cycles. NBER Working Paper 12190.

Drazen, A., Eslava, M., 2010. Electoral manipulation via voter-friendly spending: theory and evidence. J. Dev. Econ. 92 (1), 39-52. https://doi.org/10.1016/j.jdeveco. 2009.01.001.

Drazen, A., Eslava, M., 2013. Programmatic targeting. Working Paper.

Drazen, A., Ilzetzki, E., 2013. Kosher Pork, mimeo, University of Maryland and LSE.

Ferejohn, J., 1986. Incumbent performance and electoral control. Public Choice 50, 5 25. https://doi.org/10.1007/BF00124924.

Fudenberg, D., Tirole, J., 1995. A theory of income and dividend smoothing based on incumbency rents. J. Polit. Econ. 103 (1), 75-93.

Gavazza, A., Lizzeri, A., 2009. Transparency and economic policy. Rev. Econ. Stud. 76 1023-1048. https://doi.org/10.1111/j.1467-937X.2009.00547.x.

Grossman, G., Helpman, E., 1994. Protection for sale. Am. Econ. Rev. 84 (4), 833-850.

Lindbeck, A., Weibull, J., 1987. Balanced-budget redistribution as the outcome of political competition. Public Choice 52 (3), 273-297. https://doi.org/10.1007/ BF00116710.

Lizzeri, A., 1999. Budget deficits and redistributive politics. Rev. Econ. Stud. 66 (4), 909-928. https://doi.org/10.1111/1467-937X.00113.

Lizzeri, A., Persico, N., 2005. The drawbacks of electoral competition. J. Eur. Econ. Assoc 3 (6), 1318-1348.

Martimort, D., 2001. Optimal taxation and strategic budget deficit under political regime switching. Rev. Econ. Stud. 68 (3), 573-592. https://doi.org/10.1111/ 1467-937X.00181.

Maskin, E., Tirole, J., 2004. The politician and the judge: accountability in government. Am. Econ. Rev. 94 (4), 1034-1054. https://doi.org/10.1257/0002828042002606.

Maskin, E., Tirole, J., 2007. Public-private partnerships and government spending limits. Int. J. Ind. Organ. 26 (2), 412-420. https://doi.org/10.1016/j.ijindorg.2007.05. 004.

Mirrlees, J., 1971. An exploration in the theory of optimum income taxation. Rev. Econ. Stud. 38 (2), 175-208. https://doi.org/10.2307/2296779. 
Myerson, R., 1993. Incentives to cultivate favored minorities under alternative electoral systems. Am. Polit. Sci. Rev. 87 (4), 856-869. https://doi.org/10.2307/ 2938819.

Osborne, M., Slivinski, A., 1996. A model of political competition with citizencandidates. Q. J. Econ. 111 (1), 65-96. https://doi.org/10.2307/2946658.

Panova, E., 2009. Informative Campaign Promises, Mimeo, CIRANO. SSRN: http://Ssrn.Com/Abstract=1079693. DOI: 10.2139/Ssrn.1079693.

Peltzman, S., 1992. Voters as fiscal conservatives. Q. J. Econ. 107 (2), 327-361.

Persson, T., Svensson, L., 1989. Why a stubborn conservative would run a deficit: policy with time-consistent preferences. Q. J. Econ. 104 (2), 325-345. https://doi.org/10. $2307 / 2937850$.
Prat, A., 2002. Campaign advertising and voter welfare. Rev. Econ. Stud. 69, 997-1017. Robinson, J.A., Torvik, R., 2005. White elephants. J. Public Econ. 89, 197-210. https:// doi.org/10.1016/j.jpubeco.2004.05.004.

Rogoff, K., 1990. Equilibrium political budget cycles. Am. Econ. Rev, 80 (1), 21-36.

Rogoff, K., Sibert, A., 1988. Elections and macroeconomic policy cycles. Rev. Econ. Stud. 55, 1-16. https://doi.org/10.2307/2297526.

Velasco, A., 2000. Debts and deficits with fragmented fiscal policymaking. J. Public Econ. 76 (1), 105-125. https://doi.org/10.1016/s0047-2727(99)00054-7. 